\title{
Taxol as chemical detoxificant of aflatoxin produced by aspergillus flavus isolated from sunflower seed
}

\author{
Narasimhan Banu ${ }^{1 *}$, Johnpaul Muthumary ${ }^{2}$ \\ ${ }^{1}$ Department of Biotehnology, Vels University, Pallavaram, Chennai, India; *Corresponding Author: banunkl@yahoo.com \\ ${ }^{2}$ Centre for Advanced Studies in Botany, University of Madras, Chennai, India
}

Received 24 November 2009; revised 10 March 2010; accepted 12 March 2010.

\begin{abstract}
Aflatoxins are the potent toxic, mutagenic, heterogenic and carcinogenic metabolites produced by species of $A$. flavus and $A$. parasiticus. In the present study, an attempt has been made to prevent aflatoxin production using an anticancerous drug taxol. Taxol (Paclitaxel) is a well known drug for its anticancerous property mainly to treat breast and ovarian cancers. It was obtained from Taxus brevifolia and it was also obtained from the endophytic fungi present in Taxus brefivolia [1]. Therefore, this drug is specifically selected to screen its activity on the control of $A$. flavus and AFB1 production at various concentrations. Among the 6 concentrations used, $3 \mu \mathrm{g}$ of taxol was found to be suitable to control the growth and AFB1 production. The content of AFB1 found at this concentration was $6 \mathrm{ppm}$ by TLC and $6.3 \mathrm{ppm}$ by HPTLC. The complete elimination of AFB1 might require higher concentrations of taxol.
\end{abstract}

Keywords: Aflatoxins; Taxol; Anticancerous Drug; Liver Cancer

\section{INTRODUCTION}

Aflatoxins are the potent toxic, mutagenic, heterogenic and carcinogenic metabolites produced by species of $A$. flavus and A. parasiticus in food and feed, especially the oil seeds and their products, both at pre and post harvest conditions. Their occurrence in food and feed materials has caused not only health hazards in animals and humans but also economic losses especially to the exporting countries. They are initially classified as human carcinogens by the International Agency on Research in Cancer in 1993 and further epidemiological experimental research continues to show a strong link between aflatoxin exposure and hepato cellular carcinoma (HCC).

Although the prevention of mycotoxin contamination in the field is the main goal of agricultural and food industries, under certain environmental conditions the contamination of various commodities with fungi like Fusarium, Aspergillus, Alternaria and Penicillium and their mycotoxins are unavoidable for producers. Decontamination/detoxification procedure is useful in order to recuperate mycotoxin contaminated commodities. The ideal decontamination procedure should be easy to use, inexpensive and should not lead to the formation of compound that are still toxic, or may reverse to reform the parent mycotoxin or alter the nutritional and palatability properties of the grain or grain products. The frequent occurrence of aflatoxins in food materials poses a serious threat to the consumers. Therefore, a considerable concern has been shown for prevention of the mycotoxins [2]. Hepatocellular carcinoma (HCC) is one of the most prevalent cancers worldwide with incidence rates highest in geographical regions of Africa and Asia exhibiting climatic similarities of high heat, humidity and poor food storage conditions. Reports have shown that aflatoxins causes primary liver cancer in humans on a worldwide basis [3-5]. The International Agency for Research on Cancer [6] has declared AFB1 to be class I carcinogen, on the basis of animal assays. Hence approaches involving physical [7-9] chemical and biological [10-15] methods have been made to detoxify aflatoxins in food and feedstuffs in the recent past. In India, mycotoxin contamination in food and its control were extensively studied by Bilgrami and his associates [16].

Examination of physico-chemical and biochemical characteristics of AFB1 molecule reveals two important sites for toxicological activity [17]. The first site is the double bond in position c-8, 9, of furo-furan ring. The aflatoxin-DNA and protein interactions, which occur at this site, alter the normal biochemical functions of these macromolecules leading to deleterious effects at the cellular level. The second reactive group is the lactone-ring in the coumarin moiety. The lactone ring is easily hy- 
drolyzed; it is therefore a vulnerable site for degradation. Hence the degradation treatments should be aimed at removing the double bond of the terminal furan ring or in opening the lactone ring. Once the lactone ring is opened, further reactions could occur to alter the binding properties of the terminal furan ring to DNA and proteins.

Structural degradation or inactivation of aflatoxins has been found to be possible by the use of chemicals such as chlorinating agents (sodium hypochlorite, chlorine dioxide and gaseous chlorine), oxidizing agents $\left(\mathrm{H}_{2} \mathrm{O}_{2}\right.$, ozone, sodium bisulfite) and hydrolytic agents-acids (organic and inorganic) and alkalies (sodium hydroxide, ammonium hydroxide, potassium hydroxide, etc.). Some of these chemicals are already being used in food industry and are less prone to consumer resistance [18]. However, according to Park and Liang [8], most of these chemicals are impractical and are particularly unsafe because they form toxic residues or damage nutrient content, flavour, odour, color, texture or functional properties of the product.

Among different processes, ammoniation process has been extensively worked out and largely accepted in spite of certain resulting nutritional losses. Liquor ammonia, gaseous ammonia, in situ liberation of ammonia by reaction of urea and urease as well as reacting amino methylamine with lime has been used.

The noteworthy losses affecting the nutritional quality of ammoniated animal feeds include $10 \%$ reduction of protein quality [19], an irreversible reduction in the degree of unsaturation in lipids [20], a significant drip in lysine and methionine content [21,22]. The presence of residual toxicity arising from hydrolyzed products [23] along with the potential for covalent bonding of AFB1 to proteins [24] and the loss in nutritional quality, make the ammoniation treatment processes seem less acceptable. However, under defined conditions the treatment of grains (peanuts, cotton seed, corn) and their meals with ammonia appears to be a commercially viable approach to detoxification of aflatoxins to the extent of 99\% [8] particularly for feed purposes.

Ammonia degradation proceeds through hydrolysis of lactone ring, and is followed by decarboxylation to produce non-toxic compounds. Due to severity of aflatoxins contamination in selected agricultural commodities, in various locales, specific decontamination processes have been approved and put into use [8,25]. Ammoniation of feeds is authorized by Food and Drug Administration of the U.S.A. In the U.S.A., Arizona, California and Texas permit the ammoniation of cotton seed products, and Texas, North Carolina, Georgia and Alabama have approved the use in aflatoxin-contaminated corn. Mexico and South Africa have approved the procedure for use on corn. Treated peanut meal is widely used in animal feeds in Europe and elsewhere; consequently the process is routinely used in France, Senegal, Sudan and Brazil. Several member countries of the European Community import ammonia treated peanut meal on a regular basis. Ammonia treatment processes for feed mill and at farm level have been worked out intensively by Park et al. [25]. Low ammonia concentration (0.2 to $2.0 \%)$ at high pressure (35-50 psi) and high temperature $\left(80-120^{\circ} \mathrm{C}\right.$ would require less time (20-60 minutes) as compared to high ammonia concentration (1-5\%) at atmospheric pressure, ambient conditions needed more time (14-21 days) for treating feed materials containing 12-16\% moisture [25] at feed mill level and form level, respectively. Shannaz and Ghaffar [26] studied the use of ammonia gas in the reduction of aflatoxin and aflatoxin producing fungi in sunflower seeds. Use of ammonia gas reduced the seed germination but infection of $A$. flavus decreased with consequent reduction in aflatoxin production. Feeding lactating cows with ammoniated peanut meal can result in reduced levels of AFM1 in milk of cows [27]. Namazi et al. [28] demonstrated that 0.9$1.0 \%$ ammonia inhibited fungal growth together with aflatoxin production.

Pathological and histo-pathological examinations made with experimental and farm animals fed with ammoniated meals did not show any signs of aflatoxicosis. Also there were no differences in egg production and immunological responses in poultry. Sodium bisulfite can react with aflatoxin B1, G1, M1 and aflatoxicol at various temperatures and concentrations at various times to form water-soluble products [29]. Potassium bisulphite is a common food preservative and does not pose any consumer resistance problem [30]. Aflatoxin containing copra at moisture contents of $24 \%$ and $7 \%$ was effectively detoxified by ammonium hydroxide ( $>97 \%$ and 89\% reduction, respectively) [31]. Sharma et al. [32] prevented aflatoxin formation in the commodities like peanut and corn samples by the treatment with an aqueous solution of 2-chloroethylphosphoric acids. Bullerman [33] studied the effects of cinnamon on growth and aflatoxin production by known toxigenic strains of $A$. parasiticus. It was observed that the cinnamon is an effective inhibitor of aflatoxin production even though mycelium growth may be permitted.

Aflatoxin production by Aspergillus parasiticus was markedly checked by O-vanillin on the cereals and oil seeds by Bilgrami et al. [34]. Maximum inhibition was recorded on rice (85.6\%) followed by groundnut (76.25\%), wheat (54.2\%), maize (52.3\%) and mustard (51.1\%). O-vanillin did not have any pronounced effect on seed germination.

The prevention of aflatoxin producing fungi and afla- 
toxin through some known anticarcinogenic compounds viz., Redoxon (Ascorbic acid $0.1 \mathrm{~g} / \mathrm{ml}$ ) [35] and Serpasil (Reserpine $2.5 \mathrm{mg} / \mathrm{ml}$ ) [36] at different concentrations [37]. It is evident that both these drugs had shown inhibitory effects on aflatoxin production at all concentrations though in varying degrees.

Ozone effectively degraded AFB1 and AFG1 in 4\% dimethyl sulfoxide at room temperature within a few minutes. The treated products were confirmed to be non-toxic by various methods. It is reported to reduce AFB1 levels by $91 \%$ in cottonseed meal containing 22\% moisture after treatment at $100^{\circ} \mathrm{C}$ for $2 \mathrm{~h}$; however, with peanut meal (30\% moisture) the reduction was only $78 \%$ after exposure to ozone for $1 \mathrm{~h}$. [38]. The destruction and detoxification of aflatoxin B1, B2, G1 and G2 (50 $\mu \mathrm{g} / \mathrm{ml}$ in $4 \%$ dimethyl sulfoxide) with ozone were confirmed by Maeba et al. [39].

\section{MATERIALS AND METHODS}

\subsection{Chemical Method}

\subsubsection{Decontamination/Detoxification by Taxol}

Taxol is an anti cancerous drug obtained from Taxus brevifolia. Authentic sample of taxol (paclitaxel) was obtained from Sigma chemicals. A sample of $0.02 \mathrm{mg}$ was dissolved in $1 \mathrm{ml}$ of $100 \%$ methanol. From this stock different concentration of taxol viz., 0.5, 1.0, 1.5, 2.0, 2.5 and $3.0 \mu \mathrm{g}$ was taken and added to $100 \mathrm{ml}$ of Yeast Extract Sucrose medium (2\% yeast, 20\% sucrose) [40] separately. Then the medium was inoculated with a disc of Aspergillus flavus isolate from the surface sterilized sundried sunflower seed used for oil crushing and incubated for 8 days at $30^{\circ} \mathrm{C}$ as a stationary culture.

After 8 days, the cultures were killed and the culture filtrate was filtered through Whatman's No.1 filter paper. One hundred milliliter of culture filtrate was extracted thrice with equal volume of chloroform. The chloroform extract was dried over rotary evaporator. The final residue was dissolved in $0.2 \mathrm{ml}$ of chloroform. The same procedure was followed for control without adding taxol.

\subsubsection{Quantification of Aflatoxin B1 by TLC}

Five, 10, 20 and $40 \mu$ l of the above extracts were applied to pre-coated TLC plates (Merck) along with the standard aflatoxin B1. The plates were developed in a tank containing chloroform: acetone in the ratio of 88:12. After the development, the plates were viewed under long UV light at $365 \mathrm{~nm}$. Blue-fluorescence similar to standard aflatoxin B1 indicated the presence of aflatoxin B1. Quantification of aflatoxin B1 was made by evaluating on the plate itself using long UV light. The role of taxol on detoxification was determined by quantifying the intensity of blue fluorescence of aflatoxin B1.

\subsubsection{High Performance Thin Layer Chromatography}

Twenty micro liter of the above sample extracts were loaded onto pre-coated silica gel plate. The plate was developed in a saturated tank containing tertiary butyl methyl ether: methanol: water in a ratio of 9.6: 0.3: 0.1 . The developing distance of the plate was up to $80 \mathrm{~mm}$. The developed plates were scanned in a Camag TLC Scanner 3 at $366 \mathrm{~nm}$. The presence of blue-fluorescence indicated the presence of aflatoxin and confirmed with authentic sample.

\section{RESULTS AND DISCUSSION}

An attempt has been made in the present investigation to prevent aflatoxin production using an anticancerous drug taxol. Taxol (Paclitaxel) is a well known drug for it anticancerous property. It was obtained from Taxus brevifolia and it was also obtained from the endophytic fungi present in Taxus brefivolia [1], Pestalotiopsis terminaliae, an endophyte of Terminalia arjuna [41], and Pestalotiopsis versicolor and Phyllosticta murrayicola, a pathogenic fungi [42]. It is mainly used to treat breast and ovarian cancers. Therefore, this drug is specifically selected to screen its activity on the control of A. flavus and AFB1 production at various concentrations.

From authentic taxol (0.02 mg) (Sigma chemicals), $0.5,1.0,1.5,2.0,2.5$ and $3.0 \mu \mathrm{g}$ concentrations were selected and amended with YES medium containing $A$. flavus isolate. This isolate was used as control, its dry weight was $3.9 \mathrm{~g}$ and its AFB1 content was $36 \mathrm{ppm}$ (Figure 2, Table 1). Except $2.5 \mu \mathrm{g}$ concentration of taxol, all the other concentrations showed marked reduction in the mycelial dry weight and AFB1 production. But there was no correlation between the mycelial dry weight and the AFB1 production. The dry weight of the mycelium ranged from 2.6-4.6 g (Table 1).

Among the 6 concentrations used, $3 \mu \mathrm{g}$ of taxol was found to be suitable to control the growth and AFB1 production (Table 1, Figure 8). The content of AFB1 found at this concentration was 6 ppm by TLC and 6.3 ppm by HPTLC. The complete elimination of AFB1 might require higher concentrations of taxol (Figures 1-8). This study indicate that the chemical taxol was a effective inhibitor of aflatoxin production even though mycelial growth may be permitted. Taxol is quite expensive drug and we could not take this drug as food additives but the availability of Sargassum wightii is inexpensive and safe [15].

The U.S. FDA has currently established action levels (max) of aflatoxin to be $20 \mathrm{ppb}$ for human foods (except milk), 0.5 ppb for milk, 20 ppb for animal feeds, except some cases of feeds meant for maturing and finishing 
Table 1. Quantification by TLC and HPTLC.

\begin{tabular}{|c|c|c|c|c|}
\hline \multirow{2}{*}{ S.No. } & \multirow{2}{*}{$\begin{array}{c}\text { Concentration } \\
\text { of Taxol }(\mu \mathrm{g})\end{array}$} & \multirow{2}{*}{$\begin{array}{l}\text { Mycelial dry } \\
\text { weight (g) }\end{array}$} & \multicolumn{2}{|c|}{ Level of Aflatoxin B1 (ppm) } \\
\hline & & & $\begin{array}{l}\text { Quantifica- } \\
\text { tion by TLC }\end{array}$ & $\begin{array}{c}\text { Quantification } \\
\text { by HPTLC }\end{array}$ \\
\hline 1 & 0.5 & 2.9 & 8 & 9.2 \\
\hline 2 & 1.0 & 2.7 & 12 & 11 \\
\hline 3 & 1.5 & 2.6 & 16 & 15 \\
\hline 4 & 2.0 & 3.6 & 12 & 12 \\
\hline 5 & 2.5 & 4.6 & 12 & 11 \\
\hline 6 & 3.0 & 2.9 & 6 & 6.3 \\
\hline Control & - & 3.9 & 30 & 36 \\
\hline
\end{tabular}

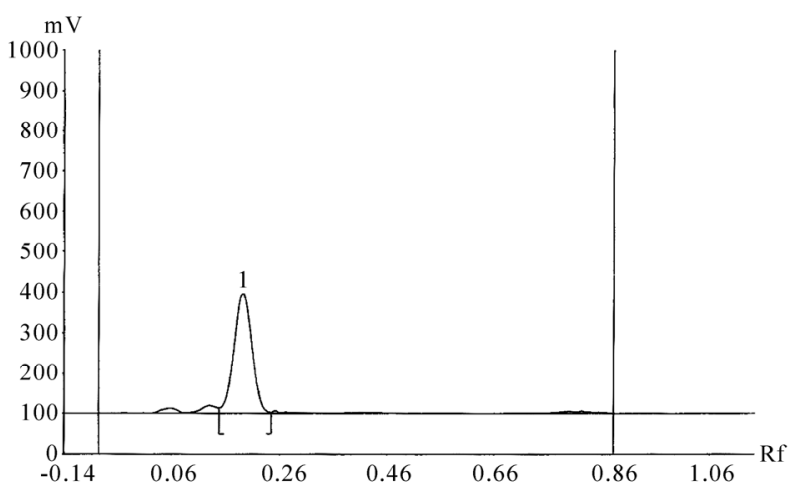

Figure 4. Aspergillus flavus with $1 \mu \mathrm{g}$ of Taxol.
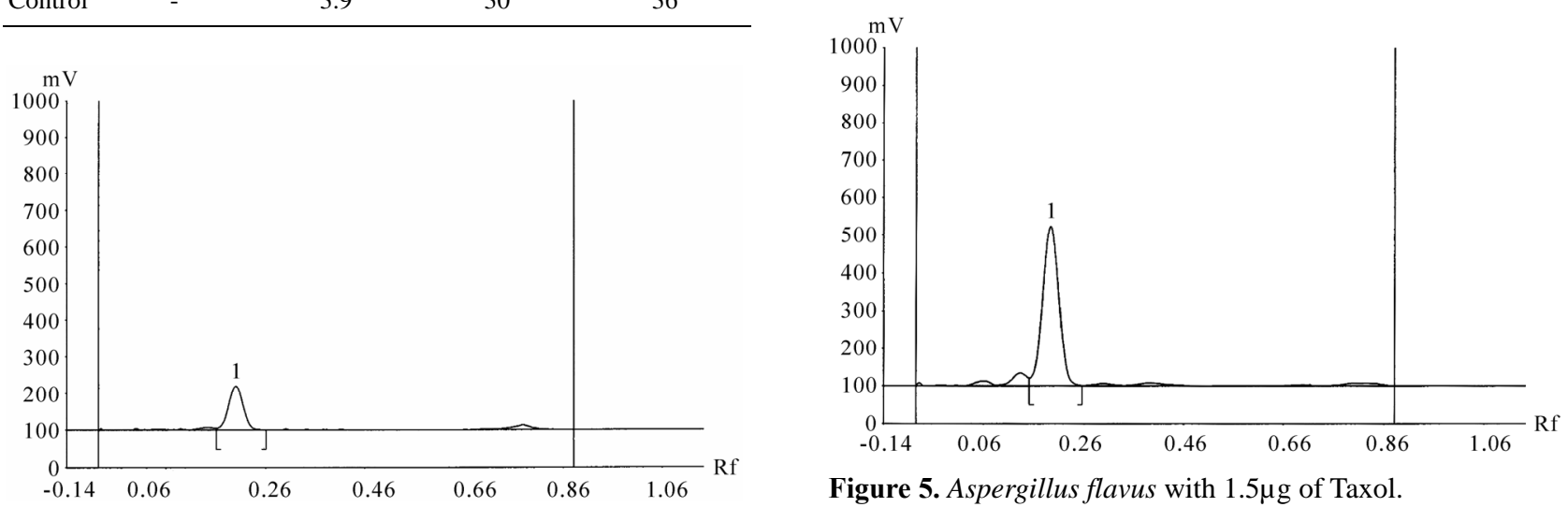

Figure 5. Aspergillus flavus with 1.5 $\mathrm{ug}$ of Taxol.

Figure 1. Authentic Aflatoxin B1.
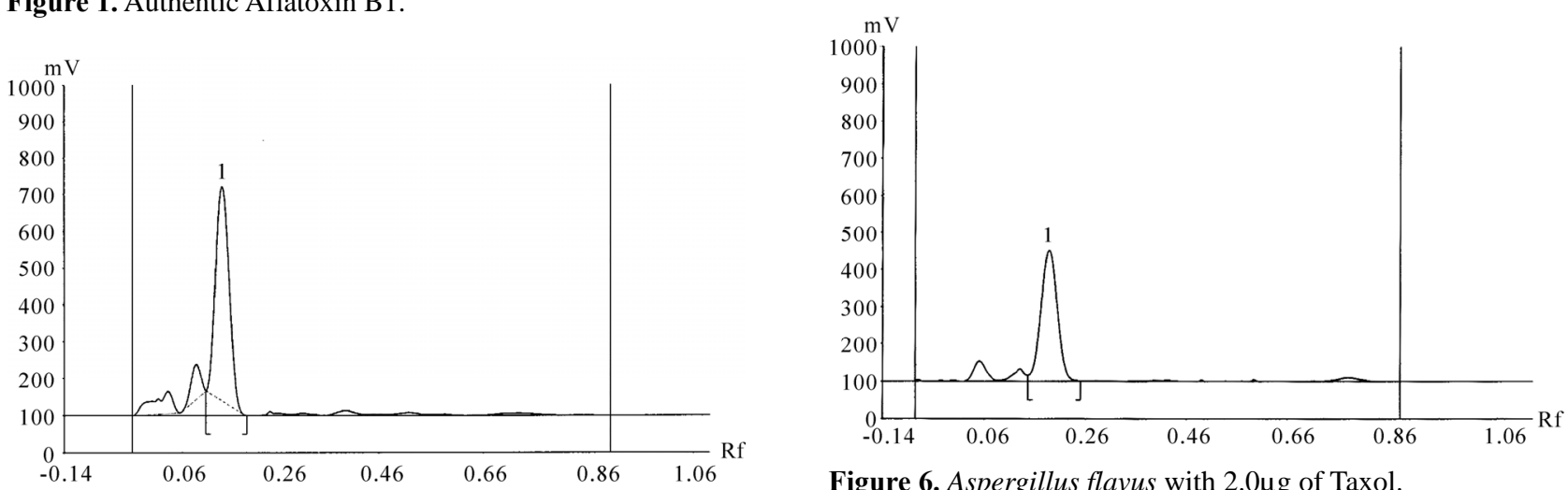

Figure 6. Aspergillus flavus with 2.0 $\mathrm{ug}$ of Taxol.

Figure 2. Control.

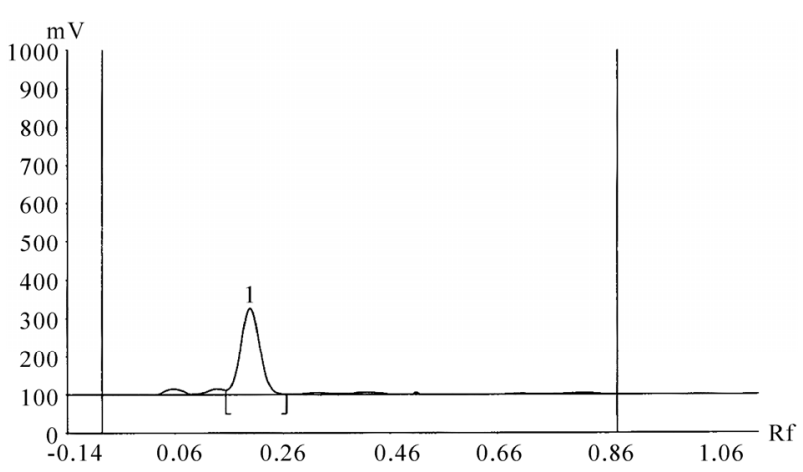

Figure 3. Aspergillus flavus with $0.5 \mu \mathrm{g}$ of Taxol.

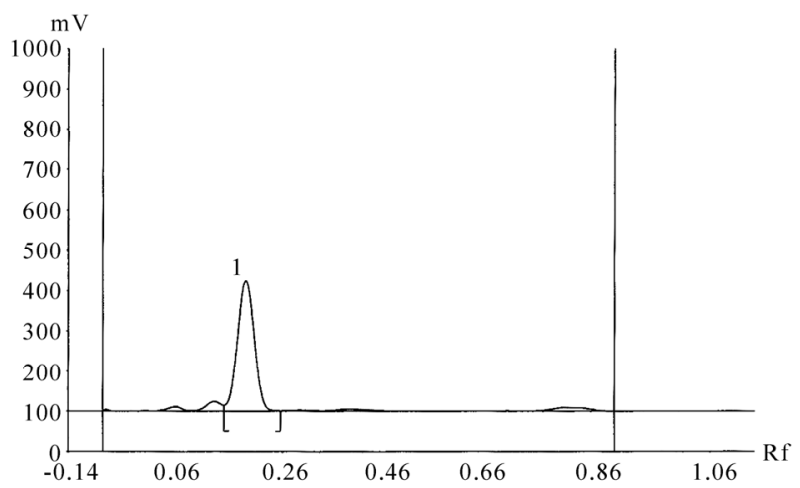

Figure 7. Aspergillus flavus with $2.5 \mu$ g of Taxol. 


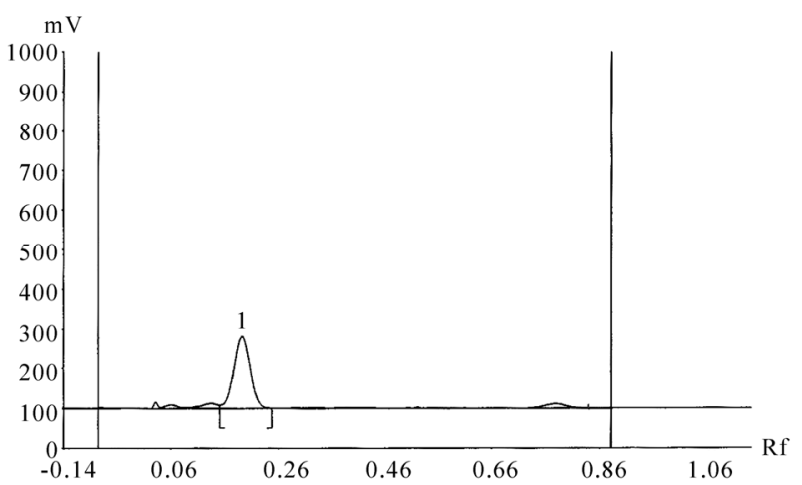

Figure 8. Asper.gillus flavus with $3.0 \mu \mathrm{g}$ of Taxol.

of meat animals, which varied from 100 to $300 \mathrm{ppb}$ [8].

From the viewpoint of health and economics, it is imperative that such low levels of aflatoxin are prescribed to follow up. To achieve such low levels, decontamination/ detoxification procedures are useful in order to recuperate mycotoxin contaminated commodities. The ideal decontamination procedure should be easy to use, inexpensive and should not lead to the formation of compounds that are still toxic or may reverse to reform the parent mycotoxin or alter the nutritional and palatability properties of the product. Hence approaches involving physical and biological methods have been made to detoxify aflatoxin in food and feedstuffs by many workers.

It was reported by Dollear [38] that in the case of groundnut oil, the oils were alkali refined, the soap stock removed and the oils subjected to two washing. No aflatoxin could be detected in $100 \mathrm{ml}$ of the refined, washed oils. It is evident that conventional processing practices remove completely any aflatoxin that may be found in crude oils. Banu and Muthumary [43] were also found the absence of fungal spores and aflatoxin in refined oil collected from Tamil Nadu Agro Industries Corporation. Chlorophyllin (CHL) has been found to be a safe and effective agent for chemoprevention in humans exposed to aflatoxin [44]. Substitution of antifungal and aflatoxin inhibitory chemicals by natural compounds such as thyme oils is recommended [45]. Examination of various concentrations of thyme essential oils on the growth of $A$. parasiticus showed promising prospectus on the utilization of natural plant oils and extracts.

Prevention of aflatoxin elaboration has received considerable attention. Various fungicides, fumigants and chemicals [46,47], plant extracts [48], antibiotics [49] have been suggested for controlling the growth of aflatoxin producing fungi as well as aflatoxin production. Ranjan and Sinha [37] used two anticarcinogenic compound viz., Redoxon [35] and Serpasil [36] on AFB1 production and A. flavus control. Complete inhibition of AFB1 was noticed at higher concentration of redoxon. Combination of serpaisl and redoxon also significantly inhibited aflatoxin production as well as mycelial growth.

\section{CONCLUSIONS}

By this study, it is evident that the taxol had inhibitory effects on aflatoxin production at all the concentrations mentioned though in varying degrees. It is apparent from this study that the anticarcinogenic drug taxol can also be exploited for the prevention of aflatoxin production by A. flavus.

\section{ACKNOWLEDGEMENTS}

We greatly acknowledge the Department of Science and Technology, Govt. of India for providing the financial support to carryout the research work.

\section{REFERENCES}

[1] Strobel, G.A., Hess, M., Yang, X., Ford, E. and Sidhu, R.S. (1996) Taxol from fungal endophytes and the issue of biodiversity. Journal of Industrial Microbiology and Biotechnology, 17(5-6), 417-423.

[2] Bassappa, S.C. (1983) Mycotoxins in food and feeds. In: Bilgrami, K.S., Prasad, T. and Sinha, K.K., Eds, The Allied Press, Bhagalpur, 251-275.

[3] Wogan, G.N. (1973) Aflatoxin carcinogenesis. In: Busch, J., Ed., Methods in Cancer Research, Academic Press, New York, 309-344.

[4] Stoloff, L. (1976) Occurrence of mycotoxins in foods and feeds. In: Rodricks, J.V., Ed., Mycotoxins and Other Fungal Related Food Problems, Advances in Chemical Series 149, American Chemical Society, Washington, D.C., 23-50.

[5] Angsubhakorn, S. (1992) Mycotoxins and human health risks. In: Semple, R.L., Frio, A.S., Hicks, P.A. and Lozare, J.V., Eds., An Over View. Mycotoxin Prevention and Control in Food Grains, 8-24.

[6] IARC (1986) Some halogenated hydrocarbons and pesticide exposures. In: Evaluation of the Carcinogenic Risk of Chemicals to Humans, International Agency for Research on Cancer.

[7] Park, D.L. and Stoloff, L. (1989) Aflatoxin control-how a regulatory agency managed risk from an unavoidable natural toxicant in food and feed. Regulatory Toxicology and Pharmacology, 9(2), 109-130.

[8] Park, D.L. (1993) Perspectives on mycotoxin decontamination procedures. Food Additives and Contaminants, 10(1), 49-60.

[9] Luter, L., Wysolonzil, W. and Kashyap, S.C. (1982) Journal of Food Science and Technology, 15, 236.

[10] Marth, E. and Hadpoyle, M.P. (1979) Food Technology 39, 81.

[11] Misra, R.S., Sinha, K.K. and Singh, P. (1981) Aflatoxin production by Aspergillus parasiticus (NRRL-3240) on maize seeds in competitive environment. National Academy of Science Letters, 4, 123-124.

[12] Horn, B. and Wicklow, D.T. (1983) Factors influencing 
the inhibition of aflatoxin production in corn by Aspergillus niger. Canadian Journal of Microbiology, 29(9), 1087-1091.

[13] Faraj, M.K., Smith, J.E. and Harran, G. (1993) Aflatoxin biodegradation: Effects of temperature and microbes. Mycological Research, 97(11), 1388-1392.

[14] Vilar, M.S., Kuilman-Wahls, M.E.M. and Fink-Gremmels, J. (2003) Inhibition of aflatoxin B1 mutagenicity by cyclopiazonic acid in the presence of human liver preparations. Toxicology Letters, 143(3), 229-299.

[15] Banu, N., Sridhar, S., Muthumary, J. and Rengasamy, R. (2008) Algae as biological detoxificant of aflatoxin produced by Aspergillus flavus isolated from sunflower seed. Indian Journal of Science and Technology, 1(3), 1-5.

[16] Bilgrami, K.S. and Singh, K.K. (1984) Mycotoxin contamination in food and its control. Indian Review of Life Science, 4, 19-36.

[17] Heathcote, J.G. and J.R. Hibber. (1978) Aflatoxins: Chemical and biological aspects. Elsevier Scientific Publishing Co., Amsterdam.

[18] Samarajeewa, V., Sen, A.C., Cohen, M.D. and Wei, C.I. (1990) Detoxification of aflatoxins in foods and feeds by physical and chemical methods. Journal of Food Protection, 53(6), 489-501.

[19] Thiesen, J. (1977) Detoxification of aflatoxin in groundnuts meal. Animal Food Science and Technology, 2, 67.

[20] Black, L.T., Spencer, G.F. and Brekke., O.L. (1978) Reactions of lipids in corn with ammonia. Journal of the American Oil Chemists'Society, 55(6), 526-529.

[21] Conkerton, E.J., Chapital, D.C., Lee L.S. and Ory, R.L. (1980) Effect of ammoniation on the physicochemical properties of peanut and cottonseed meals. Journal of Food Science, 45(3), 564-569.

[22] Piva, G.E., Santi, E., Pietri, A. and Fiorenti, L. (1981) Inactivation of aflatoxin B1 with chemical treatments. Rivista Italiana delle Sostanze Grasse, 58, 289-295.

[23] Schroeder, T., Zwelfer, V., Sagelsdorff, P., Friederich, U., Luthy J. and Schlatter, C. (1985) Ammoniation of aflatoxin-containing corn: Distribution, in vivo covalent deoxyribonucleic acid binding and mutagenicity. Journal of Agricultural Food Chemistry, 33(2), 311-316.

[24] Brekke, O.L., Peplinski, A.J., Norsinger, G.W., Conway, H.F., Springfellow, A.C., Mostgomerr, R.R., Siiman, R.W., Sohns, V.E. and Begley, E.B. (1979) Aflatoxin inactivation in corn by Ammonia gas: A field trial. Transactions of the Amercian Society of Agricultural Engineers, 22(2), 425-432.

[25] Park, D.L., Lee, L.S., Price, R.L. and Pohland, A.E. (1988) Review of the decontamination of aflatoxins by ammoniation. Current status and regulation. Journal of Association of Official Analytical Chemist, 71(4), 685703.

[26] Shahnaz, D. and Ghaffar, A. (1999) Use of ammonia gas in the control of Aspergillus flavus infection and aflatoxin production in sunflower seeds. Pakistan Journal of Botany, 31, 231-235.

[27] Hoogenboom, L.A., Tulliez, J., Gautier, J.P., Coker, R.D., Malcion, J.P., Nagler, M.J. and Polman, T.H. (2001) Absorption distribution and excretion of afl-derived ammoniation products in lactating cows. Food Additives and Contaminants, 18, 47-58.

[28] Namazi, M., Allameh, A., Aminshahidi, M., Nohee, A. and Malekzadeh, F. (2002) Inhibitory effects of ammonia solution on growth and aflatoxin production by Aspergillus parasiticus NRRL-2999. Acta Poloniae Toxicologia, 10, 65-72.

[29] Hagler, W.M. Jr., Hutchins, J.E. and Hamilton, P.B. (1982) Destruction of aflatoxin in corn with sodium bisulfite. Journal of Food Protection, 45, 1287.

[30] Doyle, M.P., Applebaum, R.S., Brackett, R.E. and Marth,. E.H. (1982) Physical, chemical and biological degradation of mycotoxins in foods and agricultural commodities. Journal of Food Protection, 45, 964-971.

[31] Mercado, C.J., Real, M.P.N. and Del Rosario, R.R. (1991) Chemical detoxification of aflatoxin-containing copra. Journal of Food Science, 56(3), 733-735.

[32] Sharma, A., Padwal-Desai, S.R. and Nadkarni, G.B. (1987) A new method for aflatoxin-free storage of agricultural commodities. Journal of Food Science, 52, 497-499.

[33] Bullerman, L.B. (1974) Inhibition of aflatoxin production by cinnamon. Journal of Food Science, 39, 1163-1165.

[34] Bilgrami, K.S., Sinha, K.K. and Singh, P. (1982) Prevention of aflatoxin production on some cereals and oil-seeds by O-vanillin. Current Science, 51(3), 138.

[35] Basu, T.K. (1979) “Vitamin C”. Recent Advances and aspects in virus Dis., Cancer and Lipid metabolism. Hans Huber Publishers, Burn, 95-102.

[36] Lupulescu, A.J. (1983) Reserpine and carcinogenesis inhibition of carcinoma formation in mice. National Cancer Institute, 71(5), 1071-1083.

[37] Ranjan, K.S. and Sinha, A.K. (1988) Prevention of aflatoxin elaboration through anticarcinogenic compounds. Biological Bulletin of India, 10, 35-37.

[38] Dollear, F.B., Mann, G.E., Codifer, L.P. Jr., Gardner, H.K., Koltun, S.P. and Vix, H.L. (1968) Elimination of aflatoxin from peanut meal. Journal of the American Oil Chemists' Society, 45(12), 862-865.

[39] Maeba, H., Takamoto, Y., Kamimura, M. and Miura, T. (1988) Destruction and detoxification of aflatoxins with ozone. Journal of Food Science, 53(2), 667-668.

[40] Davis, N.D., Diener, U.L. and Eldridge, D.W. (1966) Production of aflatoxin B1 and G1 by Aspergillus flavus in a semisynthetic medium. Applied Microbiology, 14(3), 378-380.

[41] Gangadevi, V. and Muthumary, J. (2009) Taxol production by Pestalotiopsis terminaliae and endophytic fungus of Terminalia arjuna (arjun tree). Biotechnology and Applied Biochemistry, 52(Pt 1), 9-15.

[42] Kathiravan, G. and Muthumary, J. (2009) Extraction of taxol, an anticancer drug from coelomycetous fungi Pestalotiopsis versicolor and Phyllosticta murrayicola. Mycologia Balcanica, 6, 55-60.

[43] Narasimhan, B. and Muthumary, J.P. (2005) Mycobiota of sunflower seeds and samples collected from vegetable oil refinery located in Tamilnadu, India. Mycological Progress, 4(3), 195-204.

[44] Egner, P.A., Muñoz, A. and Kensler, T.W. (2003) Chemoprevention with chlorophyllin in individuals exposed to dietary aflatoxin. Mutation Research, 523-524, 209216.

[45] Rasooli, I. and Abyaneh, M.R. (2004) Inhibitory effects of Thyme oils on growth and aflatoxin production by Aspergillus parasiticus. Food Control, 15(6), 479-483. 
[46] Dhanraj, K.S., Misra, R.S., Sinha K.K. and Singh, P. (1973) Journal of Indian Botanical Society, 59, 123-126.

[47] Majumdar, S.K. (1974) Final report (PL-480 project), In: Mysore, C.F.T.R.I., Eds.
[48] Bilgrami, K.S., Misra, R.S., Sinha, K.K. and Singh, P. (1980) Journal of Indian Botanical Society, 59, 123-126.

[49] Malini, R., Venkitasubramanian, T.A. and Mukerji, K.G. (1983) Mycotoxin in food and feed, Bhagalpur, Bihar. 